\title{
Force Analysis for Concrete Arch Dam Structure of Banjiang Reservoir
}

\author{
Ji Dongyu \\ Hunan Urban Construction College \\ Xiangtan, China \\ hnjdy@126.com
}

\begin{abstract}
Concrete arch dam is the main structure of water conservancy projects, which have the advantages of a artistic shape of structure and good mechanical properties, and it has been widely used in water conservancy projects. Banjiang Reservoir is located in Zijiang River two tributaries of Dongkou County, Hunan Province, which is a reservoir to generate electricity, combined with irrigation water resources and hydropower engineering. This article gives the stress and deformation distribution during construction and operation which has done the simulation analysis for concrete arch dam structure of Banjiang Reservoir using the finite element method. The results show that Concrete Arch Dam Structure of Banjiang Reservoir satisfy the design requirements. Using concrete arch dam scheme of Banjiang Reservoir River is reasonable. Basically, circumferential stress of arch dam upstream face is compressive stress. Furthermore, the arch's first principal stress which is small can meet the strength requirements, so the structure is safe and reliable.
\end{abstract}

Keywords-Banjiang reservoir; Concrete arch dam; Finite element method; Stress distribution; Simulation analysis.

\section{ENGINEERING SITUATION}

Banjiang Reservoir is located in Zijiang River two tributaries of Dongkou County, Hunan Province, which is a reservoir to generate electricity, combined with irrigation water resources and hydropower engineering[1]. The distance is $12 \mathrm{~km}$ from the site of dam to country and the controllable area of upstream of dam site is $36.4 \mathrm{~m}^{2}$. Normally, the reservoir is $39 \mathrm{~m}$. The flood level of design is $42.5 \mathrm{~m}$. and corresponding downstream water level is $15.9 \mathrm{~m}$. Check flood level is $43.1 \mathrm{~m}$, and corresponding downstream water level is $16.4 \mathrm{~m}$. Hub engineering is composed of dams, factories, irrigation and power diversion canal, flood discharge pipe and other buildings[2]. The dam is concrete singles arch dam which is scheduled circle and fixed outer radius[3]. The maximum height is $44.7 \mathrm{~m}$, and the dam bottom thickness is $15 \mathrm{~m}$. Arch section ratio of thickness to height is 0.37 , the maximum central angle $119^{\circ} 43^{\prime}$, the minimum central angle $21^{\circ}$. The concrete strength of arch class is C20.

\section{CALCUlation MODEL}

\section{A Model Parameters}

Concrete arch dam structure of banjiang reservoir uses concrete strength grade of $\mathrm{C} 20$, elastic modulus $E_{1}=25.5 \mathrm{GPa}$, poisson ratio $\mu_{1}=0.167 \quad$ [4],bulk density $\gamma_{1}=24 \mathrm{kN} / \mathrm{m}^{3}$. The rock of dam is quartz sandstone, and dam's riverbed hasn't tomographic. The elastic modulus of rock is $E_{2}=20 \mathrm{GPa}[5]$, poisson ratio $\mu_{2}=0.28$.

\section{B Model Element}

Concrete arch dam and bedrock structure model uses isoparametric block element which has 8-node[6]. The element is applied to three-dimensional model of the entity structure, have properties of plasticity, creep, swelling, stress stiffening, large deformation and large strain. The element has eight nodes and each node has three translational degrees of freedom[7-8] .

\section{Model Size}

The size of the entire calculation model is that it takes $65 \mathrm{~m}$ along the direction of the river, $55 \mathrm{~m}$ the direction of across the river, $33.6 \mathrm{~m}$ the vertical direction. The simulation range of model is $65 \mathrm{~m} \times 55 \mathrm{~m} \times 33.6 \mathrm{~m}$ (along the river $\times$ across the river $\times$ the vertical direction). The element division of arch and rock is shown in Fig .1. 


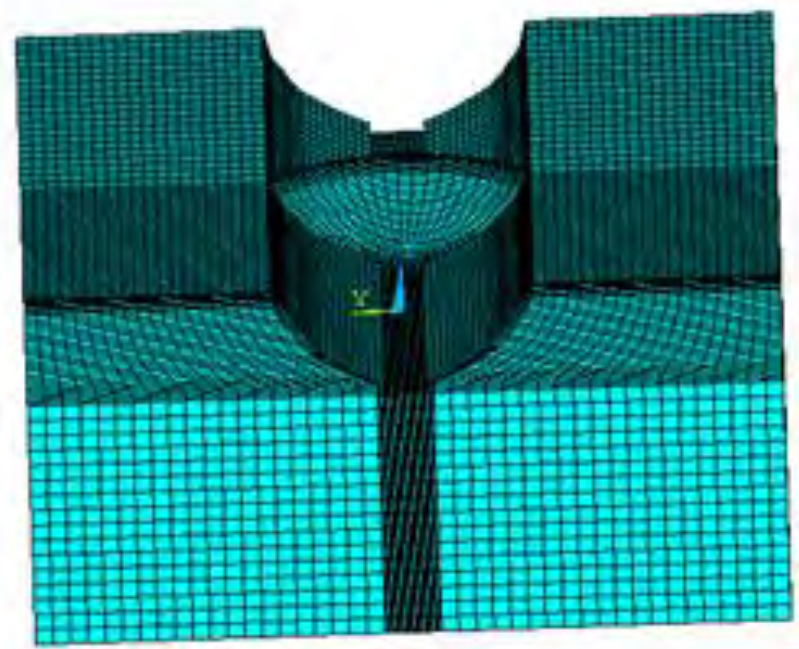

Figure 1. Arch and bedrock FEM division

\section{Calculation Condition}

Considering the mechanical characteristics of arch structure during operation[9], the following five cases are taken into account mainly: case1(structural weight),case2(structural weight and normal water level), case3(structural weight, design flood level and tail water level),case4(structural weight, checking flood level
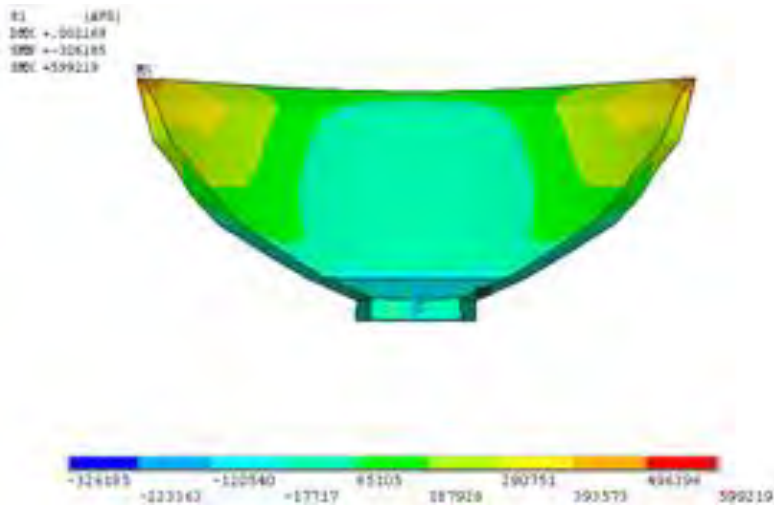

Figure 2. Cloud map of arch's first principal stress under case 1（Pa）

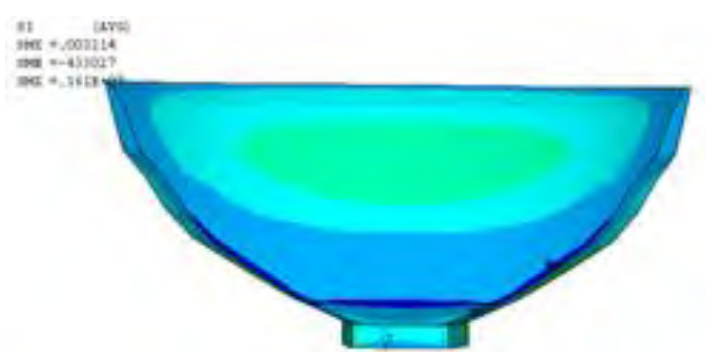

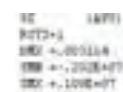

西

and tail water level),case5(structural weight, design flood level, tail water level and earthquake).

\section{ARCH STRUCTURE ANALYSIS}

\section{A Stress Analysis}

The first principal stress and vertical stress of arch various case contour map see Fig .2 to Fig .11.
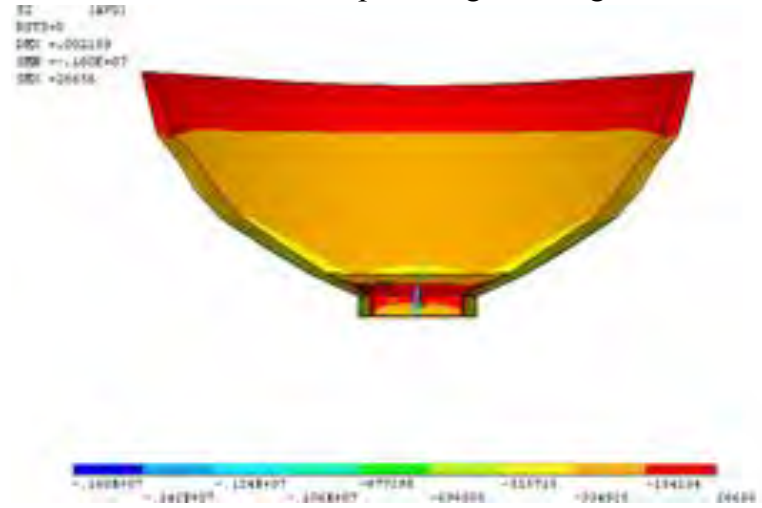

Figure 3. Cloud map of arch's vertical stress under case 1（Pa)

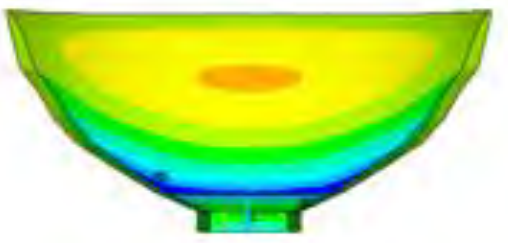

Figure 4. Cloud map of arch's first principal stress under case 2(Pa)

Figure 5. Cloud map of arch's vertical stress under case 2（Pa 

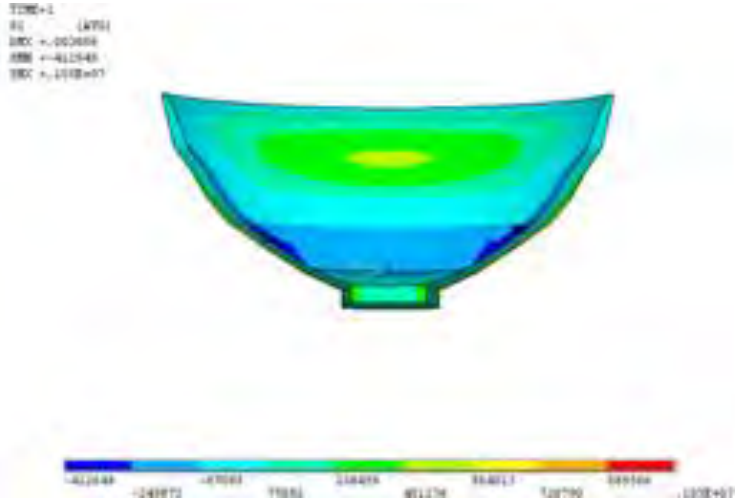

Figure 6. Cloud map of arch's first principal stress under case $3(\mathrm{~Pa})$
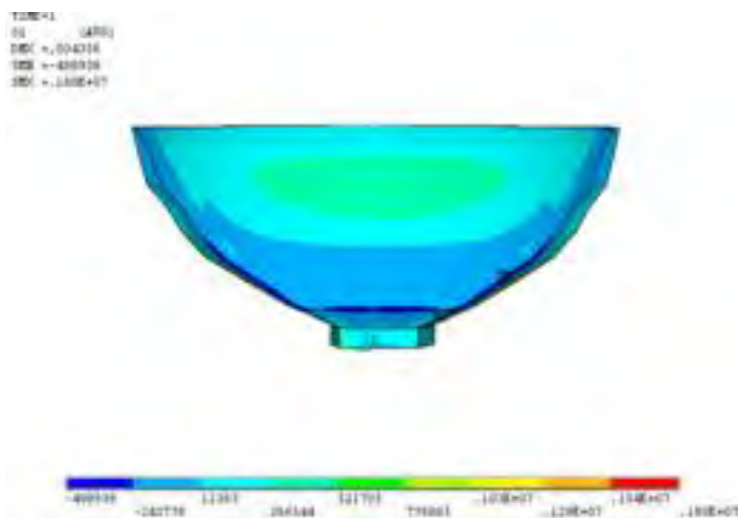

Figure 8. Cloud map of arch's first principal stress under case 4（Pa

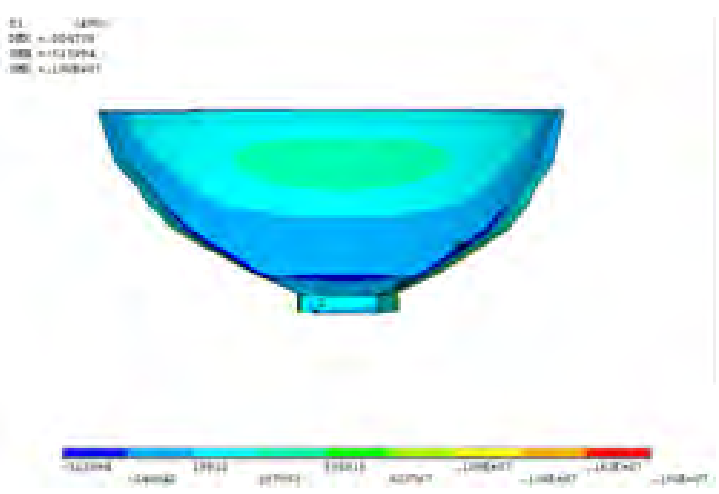

Figure 10. Cloud map of arch's first principal stress under case 5（Pa

As can be seen from Fig .2 to Fig .11, the first maximum principal stress of arch dam occurred mainly at the junction of abutment and bedrock, and the stress distribution is very complicated at the junction of bedrock and arch dam bottom. Because of water pressure and structure weight, these parts occurs the stress concentration[10]. The first principal stress of arch dam is gradually reduced from the bottom to the top of the dam, and its first principal stress increases with increasing water pressure. Vertical stress of arch emerges basically layered
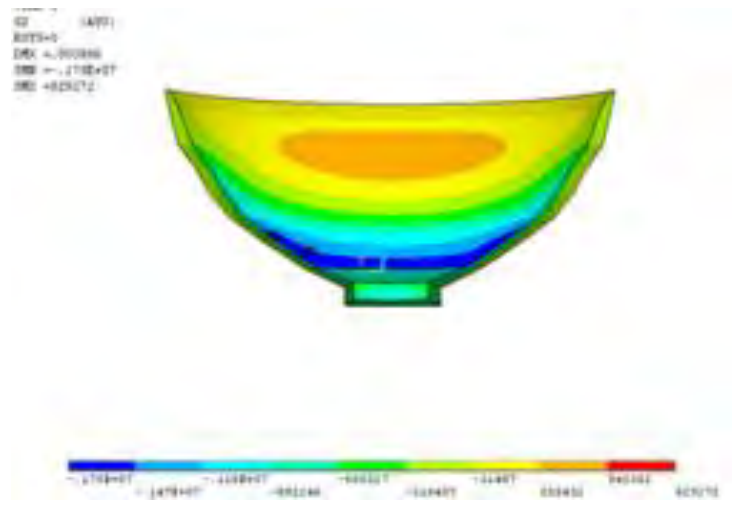

Figure 7. Cloud map of arch's vertical stress under case $3(\mathrm{~Pa})$

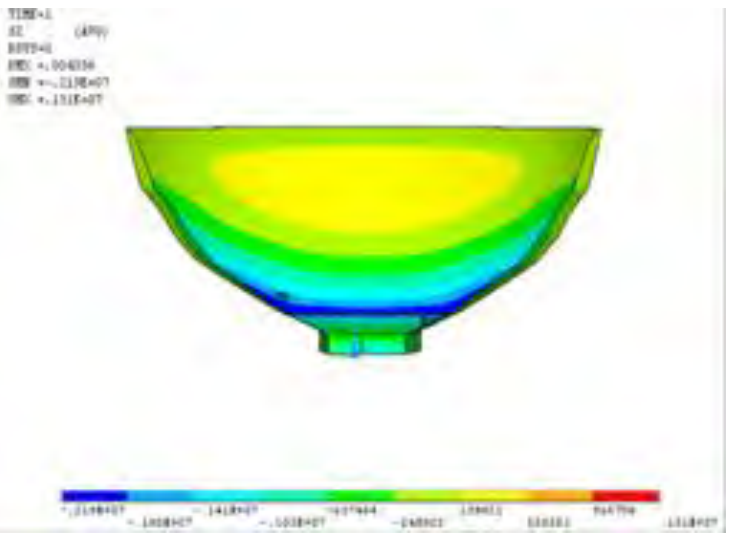

Figure 9. Cloud map of arch's vertical stress under case 4（Pa

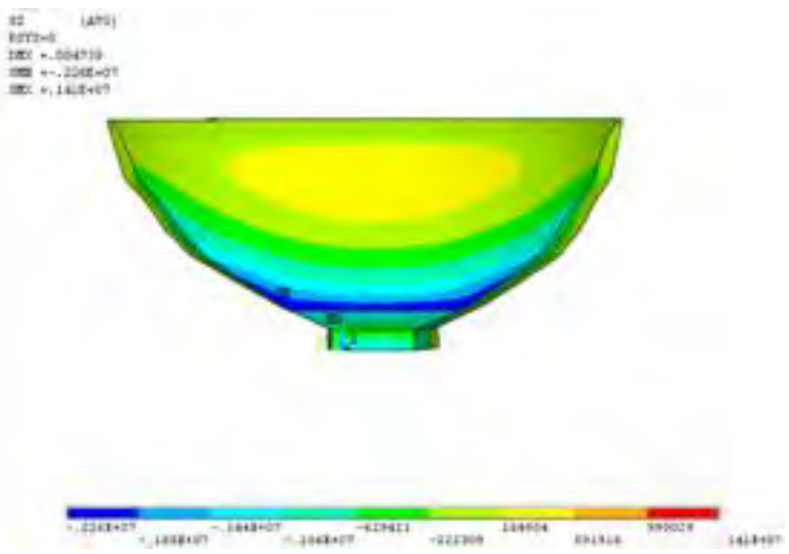

Figure 11. Cloud map of arch's vertical stress under case $5(\mathrm{~Pa})$

distribution, and vertical stress distribution is more complicated at the junction of bedrock and dam bottom.

\section{B Deformation Analysis}

By deformation analysis of concrete arch dam structure of Banjiang Reservoir, we calculated vertical displacement and radial displacement distribution maps of various case. Arch's vertical displacement and radial displacement contours for case 3 are shown in Fig .12 and Fig .13. 

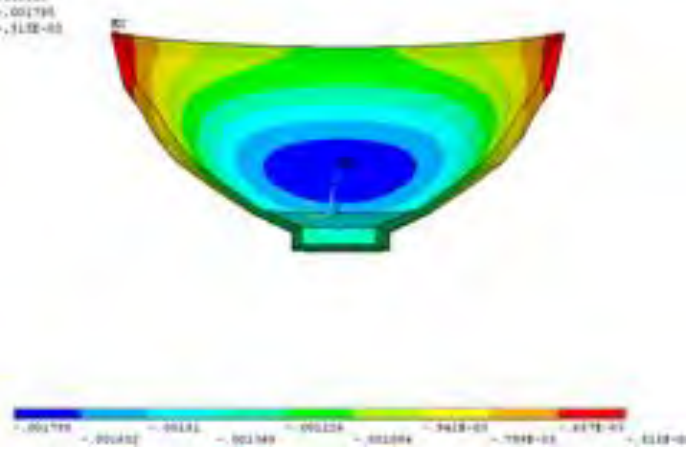

Figure 12. Cloud map of arch's vertical displacement under case 3（Pa)

As we can see from Fig .12 and Fig .13, with the increase of the water level, the radial displacement significantly increased on the key points of arch dam crown's section, but the maximum radial displacement occurs in the middle of the arch crown, while radial displacement is smaller in the top and bottom of the arch crown. Arch radial displacement is greater than the vertical displacement, and the maximum vertical displacement occurs at the top of the arch crown.

\section{CONCLUDING REMARKS}

In summary, using concrete arch dam scheme of Banjiang Reservoir River is reasonable. Basically, circumferential stress of arch dam upstream face is compressive stress. Furthermore, the arch's first principal stress which is small can meet the strength requirements, so the structure is safe and reliable.

\section{REFERENCES}

[1] Bans Sevim,Ahmet Can Altunisik,Alemdar Bayraktar et al. Estimation of Elasticity Modulus of a Prototype Arch Dam Using Experiments" Methods [J]. Journal of Materials in Civil Engineering,2012,24(4):321-329.

[2] Bans Sevim,Ahmet Can Altunisik,Alemdar Bayraktar et al. Earthquake Behavior of Berke Arch Dam Using Ambient
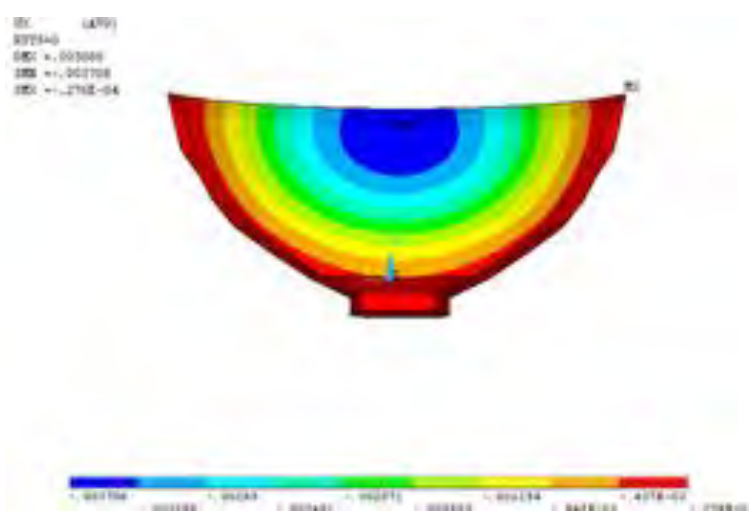

Figure 13. Cloud map of arch's radial displacement under case 3（Pa）

Vibration Test Results [J]. Journal of Performance of Constructed Facilities,2012,26(6):780-792.

[3] Khaled H. Bayagoob,Jamaloddin Noorzaei,Aeid A. Abdulrazeg et al. Coupled thermal and structural analysis of roller compacted concrete arch dam by three-dimensional finite element method [J]. Structural engineering and mechanics,2010,36(4):401-419.

[4] SL191-2008. Design Code for Hydraulic Concrete Structure[S] China Water Conservancy and Hydropower Press, 2008.

[5] Mingrong Shen, Jianfeng Chen. Rock mechanics [M]. Tongii University Press, 2006.

[6] Li Shouyi,Ding Lujun,Zhao Lijuan et al. Optimization design of arch dam shape with modified complex method [J]. Advances in Engineering Software,2009,40(9):804-808.

[7] Xucheng Wang. Finite Element Method [M]. Tsinghua University Press, 2003.

[8] Bofang Zhu. Finite Element Method Principle and Application [M]. China Water Conservancy and Hydropower Press, 1998.

[9] Seyed Mohammad Seyedpoor,Javad Salajegheh,Eysa Salajegheh et al. Shape optimal design of materially nonlinear arch dams including dam-water-foundation rock interaction using an improved PSO algorithm [J]. Optimization and engineering,2012,13(1):79-100.

[10] Bofang Zhu, Jizhang Gao, Zuyu Chen, Yisheng Li. Arch Dam Design and Research [M]. China Water Conservancy and Hydropower Press, 2002. 